\title{
Plataforma logística: estudo da viabilidade de implantação em Juiz de Fora (MG) via caracterização das mercadorias transportadas entre Minas Gerais e Rio de Janeiro
}

\author{
Suzana Quinet de Andrade Bastos ${ }^{1}$ \\ Fernando Salgueiro Perobelli ${ }^{2}$ \\ Michelle Tagliatti Maciel $^{3}$ \\ Tatiana Aparecida Sales dos Santos ${ }^{4}$
}

Resumo: Com o desenvolvimento da logística, torna-se importante a construção de centros de distribuição facilitadores do fluxo de produtos. Assim, surgem as Plataformas Logísticas. Neste contexto, o artigo busca analisar a viabilidade de implantação de uma Plataforma Logística em Juiz de Fora (MG) à luz da caracterização das mercadorias transportadas entre os Estados de Minas Gerais e Rio de Janeiro que utilizam as vias de transporte rodoviário e ferroviário que perpassam a cidade. Após a verificação da existência de um fluxo comercial internacional e inter-regional significativo e a caracterização dos produtos transportados, sugere-se a implantação, em Juiz de Fora, de uma Plataforma Logística de produtos sólidos de grande peso e baixo valor agregado.

Palavras-chave: transporte; plataforma logística; desenvolvimento regional.

Os autores agradecem a Fundação de Amparo à Pesquisa do Estado de Minas Gerais (FAPEMIG) pelo financiamento da pesquisa.

1 Doutora em Planejamento Urbano e Regional pelo IPPUR/UFRJ. Professora da Faculdade de Economia e Administração e do Mestrado em Economia Aplicada da UFJF. E-mail: quinet.bastos@ufjf.edu.br.

2 Doutor em Economia pela USP e bolsista de Produtividade CNPq - Nível II. Professor da Faculdade de Economia e Administração e do Mestrado em Economia Aplicada da UFJF. E-mail: fernando.perobelli@ufjf.edu.br.

3 Aluna do Curso de Graduação em Ciências Econômicas da FEA/UFJF e bolsista de Iniciação Científica. E-mail: michelletagliatti@hotmail.com.

4 Aluna do Curso de Graduação em Ciências Econômicas da FEA/UFJF e bolsista de Iniciação Científica. E-mail: tatitass2004@yahoo.com.br. 
BASTOS, S. \& PEROBELli, F. \& MACIEL, M. \& DOS SANTOS, T. Plataforma logística: estudo da...

\title{
Aspects of developing a logistic platform in Juiz de Fora: a viability analysis based on the main characteristics of goods transported between Minas Gerais and Rio de Janeiro
}

\begin{abstract}
The logistic development induces the construction of distribution centers that facilitate the product flow. This process leads to the building of what is known as logistic platforms. This paper analyzes the possibility of developing a logistic platform in Juiz de Fora (MG) based on the main characteristics of goods transported between Minas Gerais state and Rio de Janeiro state by highways and railways that pass along Juiz de Fora municipality. After verifying that there is a significant international and inter-regional trade flow and based on the characteristics of the transported goods, it is possible to suggest that there is role for a construction of a logistic platform at Juiz de Fora. This platform shall deal with solid goods with high weight and low aggregated value.
\end{abstract}

Keywords: transport, logistic platform; regional development.

JEL: R10; R40

\section{Introdução}

A rede logística pode ser definida como a representação físico-espacial dos pontos de origem e destino das mercadorias. Nela estão incluídos fornecedores, produção e distribuição, além da armazenagem, do transporte e de um sistema de informação.

Com a ampliação da concorrência entre as empresas e a globalização da rede logística desenvolvem-se as localizações, objetivando ampliar a eficiência de toda a cadeia de suprimento (melhorar o nível de serviços logísticos e reduzir custos) e gerar um melhor atendimento ao cliente. Assim, as Plataformas Logísticas surgem como uma alternativa eficiente. Isso porque uma Plataforma Logística tem capacidade de atender a clientes e produtos diferentes, oferecendo flexibilidade nas atividades de transporte, rapidez na movimentação de mercadorias e confiabilidade nos serviços prestados, tornando-se mais vantajosa para as empresas.

Estas vantagens podem ser aproveitadas pela região na qual a Plataforma se insere. Os impactos regionais e locais causados por uma Plataforma Logística referem-se às oportunidades de desenvolvimento local e ao aproveitamento do seu potencial. 
A criação de Plataforma Logística, segundo Duarte (2004b), envolve: a análise da situação geográfica da região; se a região oferece um meio social e um ambiente cultural e econômico favoráveis; sua infra-estrutura logística; se apresenta uma estrutura de transporte diversificada, com interligações com os grandes eixos de transportes (ligações terrestres - rodoviárias e ferroviárias -, acessos marítimos, fluviais e aéreos) e, também, a sua inserção nas relações comerciais regionais, nacionais e internacionais.

Bastos e Perobelli (2006), em uma abordagem preliminar, tentaram responder a tais questões e/ou mostraram o potencial da implantação de tal projeto em Juiz de Fora (MG). Para tal, destacaram a importância da sua localização e da sua infra-estrutura, bem como dos fluxos comerciais. De acordo com os autores, a cidade é atendida por uma rede de rodovias de elevada densidade (BR 040, BR 267 e MG 353) ${ }^{6}$ e por uma malha ferroviária operada pela MRS Logística ${ }^{7}$ Além disso, dispõe de um Aeroporto Municipal e, em breve, deverá entrar em operação o Aeroporto Regional da Zona da Mata.

Em termos da infra-estrutura logística, possui um terminal alfandegário de uso público (Estação Aduaneira do Interior - EADI - ou Porto Seco) que oferece serviços de desembaraço, de entreposto, desova, movimentação de containers e mercadorias em geral, direcionados à exportação e importação.

Bastos e Perobelli (2006), em uma segunda parte da análise, basearamse nos fluxos comerciais que cortam o município e perceberam que:

a) O Rio de Janeiro (RJ) é um ponto importante para o fluxo de comércio internacional do Estado de Minas Gerais, ou seja, em média, 32\% das exportações e 30\% das importações mineiras são realizadas através dos portos do Rio de Janeiro (RJ) e Sepetiba (RJ);

b) De forma majoritária, a distribuição do fluxo anteriormente mencionado é realizada pelas rodovias e ferrovias que cortam o município de Juiz de Fora. De acordo com Rocha (2006), apenas os fluxos provenientes das mesorregiões do Vale do Rio Doce, Vale do Mucuri e Jequitinhonha não utilizam as estradas que cruzam Juiz de Fora para distribuir seus fluxos;

c) Há um fluxo de comércio interestadual importante entre os Estados de Minas Gerais e do Rio de Janeiro que, em grande parcela,

6 A BR 040 liga o Rio de Janeiro a Belo Horizonte e Brasília. A BR 267, que se enlaça com a BR 116 (ligação entre o Sul e o Nordeste do país), é a principal ligação entre o sul de Minas, São Paulo e Zona da Mata Oriental. A rodovia estadual MG 353 disponibiliza acesso ao interior da Zona da Mata.

7 O sistema ferroviário proporciona a ligação com Rio de Janeiro (RJ), São Paulo (SP), Porto de Santos (SP), Belo Horizonte (MG), Complexo Portuário de Vitória (ES), Nordeste do País, Goiânia (GO), Brasília (DF) e estados do Sul. 
também é distribuído pela estrutura rodo-ferroviária que atende o município de Juiz de Fora. Em outras palavras, cerca de 4\% do Produto Interno Bruto (PIB) do Estado do Rio de Janeiro refere-se a importações inter-regionais realizadas pelo Estado de Minas Gerais e, aproximadamente, 7\% do PIB do Estado de Minas Gerais a importações inter-regionais realizadas pelo Estado do Rio de Janeiro.

Para Duarte (2004c), com relação ao fluxo de produtos, é relevante verificar as categorias dos produtos que circulam pela região (ou que nela são produzidos), observar se os produtos são constantes ou sazonais e analisar os corredores de transportes destes produtos e sua representatividade, tanto no cenário local quanto nacional.

Nesse contexto, o presente trabalho busca analisar a viabilidade de implantação de uma Plataforma Logística em Juiz de Fora à luz da caracterização das mercadorias transportadas entre os Estados de Minas Gerais e Rio de Janeiro. Para isso, concentra-se nos transportes rodoviário e ferroviário que atravessam Juiz de Fora.

O artigo assim se organiza: segue-se à Introdução, uma revisão de literatura sobre Plataformas Logísticas. A seguir, apresenta-se a metodologia utilizada e, posteriormente, analisa-se a viabilidade de implantação da Plataforma Logística em Juiz de Fora, considerando a categoria dos produtos que utilizam as vias de transporte que perpassam a cidade. Em Considerações Finais, há algumas sugestões de políticas públicas no âmbito municipal, que possam vir a viabilizar tal implantação.

\section{Plataformas logísticas}

Plataformas Logísticas são pontos ou áreas de rupturas das cadeias de transporte e logística nos quais se concentram atividades e funções técnicas e de valor adicional (Telecontrans 1999).

Uma Plataforma Logística é o local de reunião de tudo o que diz respeito à eficiência logística, acolhendo zonas logísticas de empreendimentos e infra-estruturas de transporte (Boudouin 1996).

A Europlataforms (1996) descreve uma Plataforma Logística como uma zona delimitada, no interior da qual se exercem, por diferentes operadores, todas as atividades relativas ao transporte, à logística (infra-estrutura para armazenagem, desembaraço aduaneiro, movimentação de mercadorias) e à distribuição de mercadorias, tanto para o trânsito nacional, como para o internacional.

Por sua vez, Rocha (2001) considera que uma Plataforma Logística é qualquer ponto onde exista a concentração de atividades relacionadas 
à logística ou atividades entre um ou mais modais, tais como, pontos de transbordo de cargas entre modais, local onde exista armazenagem ou centro de distribuição.

Trata-se, assim, de um grande centro que combina multimodalidade e otimização de fretes, com o objetivo de aumentar a eficiência, reduzir custos e ter acesso a novos mercados.

O modelo de desenvolvimento desse tipo de Plataforma tem a finalidade de aumentar a eficiência da organização logística, além de melhorar o valor e tempo dos serviços para o usuário cliente e, conseqüentemente, aumentar a competitividade (Duarte 2004c).

Segundo Batalha (1997), uma Plataforma Logística tem como objetivos diminuir o custo de transformação e depósito nas fábricas e nos setores comerciais; otimizar as entregas aos clientes; aumentar a flexibilidade e a otimização dos recursos utilizados e minimizar os custos com manuseio.

A viabilidade das Plataformas Logísticas, além de ser medida financeiramente, é analisada através do trade-off entre os objetivos estratégicos e os custos logísticos (Duarte 2004c).

Os objetivos estratégicos, segundo Ballou (2001), seriam: a redução do custo, principalmente os variáveis; a redução do capital, utilizando-se assim serviços logísticos terceirizados (operadores logísticos) e buscando um maior retorno sobre o investimento, e a melhoria nos serviços, pois o aumento das receitas depende da boa qualidade do serviço oferecido ao cliente.

Segundo Boudouin (1996), uma Plataforma Logística é composta de três subzonas com funções especiais. A subzona de serviços gerais, que engloba áreas de recepção, informação, acomodação e alimentação, bancos, agência de viagens, estacionamento, abastecimento e reparos, serviços de alfândega, administração e comunicação.

A outra subzona, a de transportes, agrupa infra-estruturas dos grandes eixos de transportes (rodoviário, ferroviário, marítimo e aéreo). E, por último, a subzona de serviços logísticos associada à prestação de serviços de fretamento, corretagem, assessoria comercial e aduaneira, aluguel de equipamentos, armazenagem, transporte e distribuição (Figura 1).

Para Duarte (2004a), o sistema logístico que engloba a Plataforma Logística pode ser dividido em segmentos de entrada e de saída. O segmento de entrada relaciona-se ao fornecimento de bens e serviços necessários para o início das operações logísticas no interior da 
Plataforma. Já o segmento de saída envolve a distribuição física dos bens e serviços até o cliente final.

Assim, por exemplo, um produto nacional que se destina ao mercado internacional deve passar por armazenagem, consolidação, expedição, transporte e desembaraço aduaneiro antes de chegar ao porto ou aeroporto no qual será embarcado.

FIGURA 1 - ESQUEMA METODOLÓGICO DA PLATAFORMA LOGÍSTICA

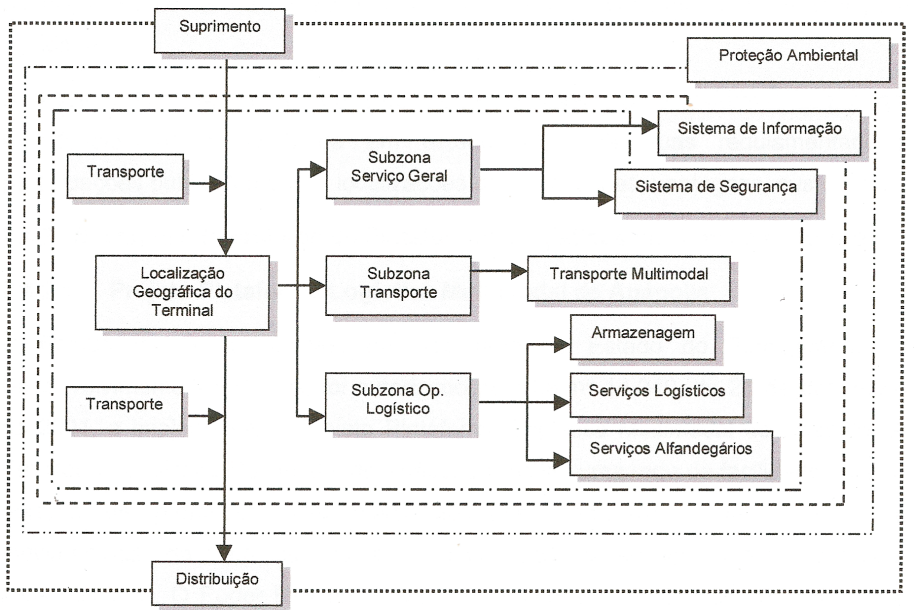

Fonte: Duarte (1999).

A Plataforma Logística pode ser vista como um macrosistema (Pólo Logístico) que envolve alguns microsistemas, tais como, transporte (transportadora, ferrovia, porto), armazéns, centros de distribuição, entre outros (Duarte 2004a:5):

Esses microsistemas podem encontrar-se em uma área muito próxima - uma região, um aglomerado - Zona Logística - ou em uma superfície muito grande como um estado ou um país. Por essa dispersão dos componentes logísticos, é muito importante um sistema de informação que gerencie toda a movimentação da mercadoria, desde o preenchimento do pedido até a entrega final do produto/serviço além, de um eficiente e flexível sistema de transporte.

Assim, a Plataforma pode se desenvolver em uma área ampla (Pólo Logístico) ou em uma área delimitada (Zona Logística). Esta área específica pode se tratar de uma empresa, de um conjunto de empresas, de uma Estação Aduaneira do Interior (EADI), de uma zona industrial ou de um porto. 


\section{Metodologia}

A caracterização das mercadorias transportadas foi realizada através da identificação das aglomerações produtivas locais, das cadeias agroindustriais e agrícolas das micro e mesorregiões do Estado de Minas Gerais (IBGE 2006; Crocco \& Galinari 2000; Andrade et al. 2000) e das concentrações de atividades econômicas das micro e mesorregiões do Estado do Rio de Janeiro (IBGE 2006; Brito 2004).

Após a identificação dos artigos produzidos em cada região, definiramse os produtos transportados pelas vias que cortam Juiz de Fora, a partir do reconhecimento do menor trajeto percorrido, dadas as rodovias (federais e estaduais) e ferrovias que escoam a produção de Minas Gerais para o Rio de Janeiro e do Rio de Janeiro para Minas Gerais.

Foi utilizado o Programa Maplink para identificar as menores rotas (menor distância) entre a principal cidade (maior PIB) de cada uma das microrregiões dos Estados de Minas Gerais e do Rio de Janeiro até a capital do Estado (Belo Horizonte e Rio de Janeiro, respectivamente).

Considerar-se-á que as mercadorias transportadas entre os Estados de Minas Gerais e Rio de Janeiro passam, por via rodoviária ou ferroviária, em grande parte por Juiz de Fora. Rocha (2006) destaca que devido à localização das mesorregiões dentro de cada Estado e à menor distância ao longo das vias pavimentadas e ferrovias, praticamente todo o escoamento de produção corta a Zona da Mata mineira, passando, assim, pela cidade.

Portanto, dentro do Estado de Minas Gerais, as mesorregiões de Campo das Vertentes, Central Mineira, Metropolitana de Belo Horizonte, Noroeste de Minas, Norte de Minas, Oeste de Minas, Triângulo, Alto do Paranaíba e a própria Zona da Mata escoam suas produções para o Estado do Rio de Janeiro através de rodovias e ferrovias que passam por Juiz de Fora.

As mesorregiões Sul e Sudoeste de Minas, apesar de utilizarem estradas mineiras na Zona da Mata, utilizam principalmente as vias de transporte paulistas. De acordo com Rocha (2006), as únicas mesorregiões do Estado a não utilizarem estradas que cruzam Juiz de Fora são Vale do Rio Doce, Vale do Mucuri e a parte nordeste do Jequitinhonha.

Através do Quadro 1, visualiza-se que o escoamento da produção das mesorregiões Vale do Rio Doce, Vale do Mucuri e da microrregião Almenara, no Vale do Jequitinhonha ocorre, principalmente, via BR 116. Destaca-se ainda o Sul e Sudoeste de Minas, que utilizam a mesma rodovia, sentido São Paulo-Rio de Janeiro, além de rodovias auxiliares que dão acesso à BR 116. Percebe-se, também, que parte da Zona da 
BASTOS, S. \& PEROBELLI, F. \& MACIEL, M. \& DOS SANTOS, T. Plataforma logística: estudo da...

Mata (microrregiões de Cataguases e Ubá) utiliza a BR 116, além da BR 120 .

QUADRO 1 - ESCOAMENTO DA PRODUÇÃO DE MINAS GERAIS PARA O RIO DE JANEIRO

\begin{tabular}{|c|c|c|c|}
\hline Mesorregiões & Microrregião & Rodovia & PIB \% \\
\hline \multirow{2}{*}{ Central Mineira } & Três Marias & BR 040 & \multirow{2}{*}{1,65} \\
\hline & Lagoa da Prata & MG 429 / MG 050 / BR 381/ BR 040 & \\
\hline \multirow{2}{*}{ Campos das Vertentes } & Barbacena & BR 040 & \multirow{2}{*}{2,24} \\
\hline & Lavras & BR 265 / BR o40 & \\
\hline \multirow{2}{*}{ Noroeste de Minas } & Unaí & MG 188 / BR o40 & \multirow[b]{2}{*}{1,78} \\
\hline & Paracatu & BR 040 & \\
\hline \multirow{2}{*}{ Vale do Mucuri } & Nanuque & BR 418 / BR 116 & \multirow{2}{*}{1,02} \\
\hline & Teófilo Otoni & BR 116 & \\
\hline \multirow{2}{*}{ Vale do Jequitinhonha } & Almenara & BR 367 / BR 116 & \multirow{2}{*}{1,39} \\
\hline & Diamantina & BR 367 / BR 259 / BR 040 & \\
\hline \multirow{2}{*}{ Vale do Rio Doce } & Governador Valadares & BR 116 & \multirow{2}{*}{7,41} \\
\hline & Ipatinga & BR 458 / BR 116 & \\
\hline \multirow{2}{*}{ Oeste de Minas } & Divinópolis & BR 050 / BR 040 & \multirow[b]{2}{*}{3,95} \\
\hline & Itaúna & BR 050 / BR 040 & \\
\hline \multirow{3}{*}{ Zona da Mata } & Juiz de Fora & BR 040 & \multirow{3}{*}{8,34} \\
\hline & Cataguases & BR 120 / BR 267 / BR o40 & \\
\hline & Ubá & BR 265 / MG 133 / MG 353 / BR 040 & \\
\hline \multirow{5}{*}{$\begin{array}{l}\text { Metropolitana de Belo } \\
\text { Horizonte }\end{array}$} & Belo Horizonte & BR 040 & \multirow{5}{*}{39,67} \\
\hline & Sete Lagoas & BR o40 & \\
\hline & Conselheiro Lafaiete & BR 040 & \\
\hline & Itabira & BR 120 / BR 381 / BR o40 & \\
\hline & Ouro Preto & BR 356 / BR o40 & \\
\hline \multirow{5}{*}{ Sul/Sudoeste de Minas } & Varginha & BR 459 / BR 116 & \multirow{5}{*}{12,23} \\
\hline & São Sebastião do Paraíso & BR 491 / BR 381 / BR 459 / BR 116 & \\
\hline & Santa Rita do Sapucaí & BR 459 / BR 116 & \\
\hline & São Lourenço & BR 383 / BR 459 / BR 116 & \\
\hline & Itajubá & BR 459 / BR 116 & \\
\hline \multirow{2}{*}{$\begin{array}{l}\text { Triângulo Mineiro/Alto } \\
\text { Paranaíba }\end{array}$} & Uberaba & BR 262 / BR 381 / BR o40 & \multirow{2}{*}{15,58} \\
\hline & Uberlândia & BR 452 / BR 262 / BR 381 / BR o40 & \\
\hline Norte de Minas & Montes Claros & BR 135 / BR o40 & 4,75 \\
\hline
\end{tabular}

Fonte: Crocco \& Galinari (2000) e Maplink (2006).

Obs: Percentual do PIB de 2004 a preços de mercado de 2005.

Com relação ao fluxo inverso de mercadorias, ou seja, entre o Estado do Rio de Janeiro e o Estado de Minas Gerais, apenas oito microrregiões, localizadas nas mesorregiões Centro Fluminense, Norte Fluminense e Noroeste Fluminense, não utilizam rotas rodoviárias que passam por 
BASTOS, S. \& PEROBELLI, F. \& MACIEL, M. \& DOS SANTOS, T. Plataforma logística: estudo da...

Juiz de Fora. São elas: Cantagalo-Cordeiro, Nova Friburgo, Santa Maria Madalena, Três Rios, Itaperuna, Santo Antônio de Pádua, Campos dos Goytacazes e Macaé. O restante das microrregiões, inclusive a mais importante (Metropolitana do Rio de Janeiro), utiliza rota rodoviária que passa pela BR 040 no trecho em que Juiz de Fora está localizada, como mostrado no Quadro 2:

QUADRO 2 - ESCOAMENTO DA PRODUÇÃO DO RIO DE JANEIRO PARA MINAS GERAIS

\begin{tabular}{|c|c|c|c|}
\hline Mesorregião & Microrregião & Rodovias & PIB \% \\
\hline \multirow{2}{*}{ Baixadas } & $\begin{array}{l}\text { Bacia de São } \\
\text { João }\end{array}$ & $\begin{array}{l}\text { RJ } 106 \text { / RJ } 162 \text { / BR } 101 \text { / BR } 493 \text { / BR } 116 \text { / RJ } 107 \text { / } \\
\text { BR 040 / BR } 356\end{array}$ & 0,37 \\
\hline & Lagos & $\begin{array}{l}\text { RJ } 102 \text { / RJ } 140 \text { / RJ } 106 \text { / RJ } 124 \text { / BR } 101 \text { / BR } 493 \text { BR } \\
116 \text { RJ } 107 \text { / BR 040 / BR } 356\end{array}$ & 1,40 \\
\hline \multirow{4}{*}{$\begin{array}{l}\text { Centro } \\
\text { Fluminense }\end{array}$} & $\begin{array}{l}\text { Cantagalo- } \\
\text { Cordeiro }\end{array}$ & $\begin{array}{l}\text { RJ } 160 \text { / RJ } 158 \text { / BR } 393 \text { / BR } 116 \text { / BR } 120 \text { / MG } 285 \text { / } \\
\text { BR } 265 \text { / BR 040 / BR } 356\end{array}$ & 0,37 \\
\hline & Nova Friburgo & $\begin{array}{l}\text { RJ } 116 \text { / RJ } 148 \text { / RJ } 144 \text { / RJ } 158 \text { / BR } 393 \text { / BR } 116 \text { BR } \\
120 \text { / MG } 285 \text { / BR } 265 \text { / BR o40 / BR } 365\end{array}$ & 0,85 \\
\hline & $\begin{array}{l}\text { Santa Maria } \\
\text { Madalena }\end{array}$ & $\begin{array}{l}\text { RJ } 146 \text { / RJ } 172 \text { / RJ } 116 \text { / RJ } 164 \text { / RJ 16o / RJ } 158 \text { / BR } \\
393 \text { / BR } 116 \text { / BR } 120 \text { / MG } 285 \text { / BR } 265 \text { / BR 040 / BR } \\
356\end{array}$ & 0,08 \\
\hline & Três Rios & BR 393 / BR o40 / BR 356 & 0,60 \\
\hline \multirow{5}{*}{$\begin{array}{l}\text { Metropolitana } \\
\text { Rio de Janeiro }\end{array}$} & Itaguaí & RJ o79 / BR 101 / BR 040 / BR 356 & 0,53 \\
\hline & $\begin{array}{l}\text { Macacu-Caceri- } \\
\text { bu }\end{array}$ & RJ 116 / RJ 122 / BR 116 / RJ 134 / BR o40/BR 356 & 0,53 \\
\hline & Rio de Janeiro & BR 040 / BR 356 & 76,99 \\
\hline & Serrana & RJ 107 / BR 040 / BR 356 & 2,07 \\
\hline & Vassouras & RJ 127 / BR 393 / BR o40 / BR 356 & 0,51 \\
\hline \multirow{2}{*}{$\begin{array}{l}\text { Noroeste } \\
\text { Fluminense }\end{array}$} & Itaperuna & $\begin{array}{l}\text { RJ } 198 \text { / BR } 356 \text { / BR } 116 \text { / BR } 356 \text { / BR } 120 \text { / BR } 356 \text { / } \\
\text { BR } 482 \text { / BR o40 / BR } 356\end{array}$ & 0,54 \\
\hline & $\begin{array}{l}\text { Santo Antônio } \\
\text { de Pádua }\end{array}$ & $\begin{array}{l}\text { RJ } 116 \text { / RJ } 200 \text { / MG } 285 \text { / BR } 116 \text { / BR } 120 \text { / MG } 285 \text { / } \\
\text { BR } 265 \text { / BR o40 / BR } 356\end{array}$ & 0,32 \\
\hline \multirow{2}{*}{$\begin{array}{l}\text { Norte } \\
\text { Fluminense }\end{array}$} & $\begin{array}{l}\text { Campos dos } \\
\text { Goytacazes }\end{array}$ & $\begin{array}{l}\text { BR } 356 \text { / BR } 116 \text { / BR } 356 \text { / BR } 120 \text { / BR } 482 \text { / BR o } 40 \text { / } \\
\text { BR } 356\end{array}$ & 1,80 \\
\hline & Macaé & $\begin{array}{l}\text { RJ } 106 \text { / BR } 101 \text { / RJ } 182 \text { / RJ } 174 \text { / RJ } 146 \text { / RJ } 172 \text { / RJ } \\
116 \text { / RJ } 164 \text { / RJ 160 / RJ 158 / BR 393 / BR } 116 \text { / BR } \\
120 \text { / MG } 285 \text { / BR } 265 \text { / BR 040 / BR } 356\end{array}$ & 2,01 \\
\hline \multirow{3}{*}{$\begin{array}{l}\text { Sul } \\
\text { Fluminense }\end{array}$} & $\begin{array}{l}\text { Baía da Ilha } \\
\text { Grande }\end{array}$ & $\begin{array}{l}\text { BR } 101 \text { / RJ } 155 \text { / RJ } 115 \text { / RJ o66 / RJ } 145 \text { / RJ } 137 \text { BR } \\
393 \text { / BR o40 / BR } 356\end{array}$ & 1,00 \\
\hline & Barra do Píraí & RJ 145 / RJ 137 / BR 393 / BR o40 / BR 356 & 0,66 \\
\hline & $\begin{array}{l}\text { Paraíba } \\
\text { Fluminense }\end{array}$ & RJ 145 / RJ 151 / BR 040 & 9,03 \\
\hline
\end{tabular}

Fonte: Centro de Informações e Dados do Rio De Janeiro (2006), Maplink (2006).

Obs: Percentual do PIB de 2004 a preços de mercado de 2005. 
A importância do fluxo de mercadorias entre Minas Gerais e Rio de Janeiro, por vias que passam em Juiz de Fora, é reforçada quando se considera que apenas 9\% do PIB total do Estado de Minas Gerais é produzido por microrregiões mineiras que não utilizam essas vias ao escoarem sua produção para o Rio de Janeiro.

Assim, a produção de Minas Gerais destinada ao Estado do Rio de Janeiro passa principalmente por Juiz de Fora, uma vez que utiliza a BR 040, rodovia federal que liga Belo Horizonte ao Rio de Janeiro.

Quanto às ferrovias, a MRS Logística é a concessionária que controla, opera e monitora a Malha Sudeste da Rede Ferroviária Federal - antiga Estrada de Ferro Central do Brasil, que possui as linhas que ligam Rio de Janeiro a São Paulo e a Belo Horizonte.

Segundo Martins (2006), com intuito de aumentar a produtividade da concessionária, os trens descem de Minas Gerais, com vagões carregados, pela Ferrovia do Aço, mais moderna, até os Portos do Estado do Rio de Janeiro e retornam vazios pela Ferrovia Centro, mais deteriorada e que corta maior número de municípios. ${ }^{8}$

Por conseguinte, o fluxo de mercadorias para exportação, em Minas Gerais, utiliza preferencialmente a Ferrovia do Aço para chegar aos portos do Estado do Rio de Janeiro, enquanto apenas a mesorregião de Campo das Vertentes e parte da mesorregião da Zona da Mata (Barbacena) utilizam a Ferrovia Centro. Entretanto, as importações são realizadas principalmente através da Ferrovia Centro (Martins 2006).

Ao examinar o PIB das oito microrregiões do Estado do Rio de Janeiro que não utilizam as vias rodo-ferroviárias que cortam Juiz de Fora, ao escoar sua produção para Minas Gerais, percebe-se que este representa menos de 6\% do total do Estado.

Isso, sobremaneira, destaca o valor dos fluxos de mercadoria entre Rio de Janeiro e Minas Gerais através dessas vias. Assim, a produção do Rio de Janeiro, que tem como destino o Estado de Minas Gerais, passa, majoritariamente, por Juiz de Fora.

\section{Caracterização das mercadorias transportadas entre Minas Gerais e Rio de Janeiro}

A caracterização das mercadorias transportadas entre os Estados de Minas Gerais e Rio de Janeiro será demonstrada considerando,

8 "Cargas originárias do Estado de Minas Gerais (ou a ele destinadas) têm acesso ferroviário ao porto através da linha de bitola larga da MRS Logística (Ferrovia do Aço)” (César 2002:79). 
separadamente, os dois sentidos de fluxo. Ou seja, inicialmente, será apresentado o fluxo de mercadorias entre Minas Gerais e Rio de Janeiro, a partir da identificação das aglomerações produtivas locais e das cadeias agroindustriais e agrícolas existentes no Estado de Minas Gerais.

Em seguida, será analisado o fluxo inverso, ou seja, as mercadorias transportadas entre o Estado do Rio de Janeiro e Minas Gerais, a partir da identificação das concentrações de atividade econômica das mesorregiões do Estado do Rio de Janeiro.

\subsection{Destino Minas Gerais-Rio de Janeiro}

O Quadro 3 é um resumo da composição das aglomerações produtivas locais, dadas as respectivas mesorregiões do Estado de Minas Gerais.

QUADRO 3 - AGLOMERAÇÕES PRODUTIVAS LOCAIS DE MG POR MESORREGIÕES/2006

\begin{tabular}{|c|c|c|}
\hline Mesorregiões & Microrregiões & Aglomerações \\
\hline Norte de Minas & Montes Claros & Papel e gráfica, química e têxtil. \\
\hline \multirow{2}{*}{$\begin{array}{l}\text { Triângulo } \\
\text { Mineiro/ Alto } \\
\text { Paranaíba }\end{array}$} & Uberlândia & $\begin{array}{l}\text { Papel e gráfica, borracha, fumo e couro, alimentos e } \\
\text { bebidas. }\end{array}$ \\
\hline & Uberaba & Mecânica, papel e gráfica, química. \\
\hline \multirow{5}{*}{$\begin{array}{l}\text { Metropolitana } \\
\text { de Belo } \\
\text { Horizonte }\end{array}$} & Sete Lagoas & Extrativa mineral. \\
\hline & Belo Horizonte & $\begin{array}{l}\text { Extrativa mineral, mineral não metálico, metalúrgica, } \\
\text { mecânica, elétrica e comunicação, transporte, papel e } \\
\text { gráfica, química, alimentos e bebidas. }\end{array}$ \\
\hline & Itabira & Extrativa mineral. \\
\hline & Ouro Preto & Extrativa mineral, elétrica e comunicações. \\
\hline & $\begin{array}{l}\text { Conselheiro } \\
\text { Lafaiete }\end{array}$ & Metalúrgica. \\
\hline Oeste de Minas & Divinópolis & Têxtil e calçados. \\
\hline \multirow{3}{*}{ Zona da Mata } & Cataguases & Têxtil. \\
\hline & Ubá & Mobiliário e madeira. \\
\hline & Juiz de Fora & Papel e gráfica, borracha, fumo e couro, têxtil. \\
\hline \multirow{2}{*}{$\begin{array}{l}\text { Vale do Rio } \\
\text { Doce }\end{array}$} & $\begin{array}{l}\text { Governador } \\
\text { Valadares }\end{array}$ & Papel e gráfica. \\
\hline & Ipatinga & Metalúrgica, papel e gráfica. \\
\hline
\end{tabular}

continua 
BASTOS, S. \& PEROBELLI, F. \& MACIEL, M. \& DOS SANTOS, T. Plataforma logística: estudo da...

\begin{tabular}{|l|l|l|}
\hline \multirow{4}{*}{$\begin{array}{l}\text { Sul/Sudoeste } \\
\text { de Minas }\end{array}$} & São Sebastião do Paraíso & Elétrica e comunicações. \\
\cline { 2 - 3 } & Varginha & Borracha, fumo e couro. \\
\cline { 2 - 3 } & Santa Rita do Sapucaí & Elétrica e comunicações. \\
\cline { 2 - 3 } & São Lourenço & Papel e gráfica. \\
\cline { 2 - 3 } & Itajubá & $\begin{array}{l}\text { Elétrica e comunicações, mecânica e } \\
\text { transporte. }\end{array}$ \\
\hline
\end{tabular}

Fonte: Crocco \& Galinari (2000).

Percebe-se, assim, que a mesorregião com maior número de aglomerações produtivas é a Metropolitana de Belo Horizonte, com destaque para a microrregião de Belo Horizonte e a Sul/Sudoeste de Minas.

Também constam no Quadro 3, apenas, aquelas mesorregiões em que foram detectadas aglomerações produtivas locais relevantes; no total, sete mesorregiões. As outras cinco mesorregiões, Noroeste de Minas, Jequitinhonha, Vale do Mucuri, Central Mineira e Campo das Vertentes, não apresentaram aglomerações produtivas relevantes via análise do Índice de Concentração (IC), calculado pelos autores Crocco e Galinari (2000).

Em relação às cadeias agroindustriais e agrícolas de Minas Gerais, temse o Quadro 4, no qual se percebe a distribuição dessas cadeias entre as mesorregiões do Estado.

QUADRO 4 - CADEIAS AGROINDÚSTRIAS E AGRÍCOLAS DE MG POR MESORREGIÕES/2006

\begin{tabular}{|l|c|}
\hline Mesorregiões & Cadeia Agroindustrial e Agrícola \\
\hline Noroeste de Minas & Mandioca. \\
\hline Norte de Minas & Carne bovina, Frutas, Algodão. \\
\hline $\begin{array}{l}\text { Triângulo Mineiro/ Alto } \\
\text { Paranaíba }\end{array}$ & $\begin{array}{c}\text { Café, Carne Suína, Carne Bovina, Carne de Frango, Produção } \\
\text { de Leite, Frutas, Cana-de-açúcar, Algodão, Soja, Milho. }\end{array}$ \\
\hline Zona da Mata & Café, Carne Suína, Carne Bovina, Carne de Frango, Frutas, \\
\hline Campo das Vertentes & Frutas. \\
\hline Central Mineira & Carne de Frango, Frutas, Arroz. \\
\hline Jequitinhonha & Frutas, Mandioca. \\
\hline Oeste de Minas & Arroz. \\
\hline Vale do Rio Doce & Carne Suína. \\
\hline Sul/ Sudoeste de Minas & Café, Carne de Frango, Frutas, Cana-de-açúcar, Feijão, Batata. \\
\hline
\end{tabular}

Fonte: Andrade \& Campello (2000). 
BASTOS, S. \& PEROBELli, F. \& MACIEL, M. \& DOS SANTOS, T. Plataforma logística: estudo da...

Pode-se verificar que Minas Gerais possui uma vasta tipologia de cadeias agroindustriais e agrícolas. A mesorregião que mais se destaca quanto à presença de tais cadeias produtivas é a do Triângulo/Alto Paranaíba.

Ao analisar os Quadros 1, 3 e 4, em conjunto, percebe-se os principais produtos das aglomerações produtivas e das cadeias agroindustrial e agrícola de Minas Gerais transportados pela BR 040 escoados para o Estado do Rio de Janeiro (Quadro 5).

QUADRO 5 - PRODUTOS MINEIROS ESCOADOS PARA O ESTADO DO RIO DE JANEIRO VIA BR 040

\begin{tabular}{|l|c|}
\hline Aglomerações Produtivas & Cadeia Agroindustrial e Agrícola \\
\hline $\begin{array}{l}\text { Papel e gráfica, química, borracha, fumo e couro, mecânica, } \\
\text { têxtil e calçado, extrativa mineral, mineral não metálico, } \\
\text { metalúrgica, mecânica, elétrica e comunicação, transporte, } \\
\text { alimentos e bebidas, mobiliário e madeira. }\end{array}$ & $\begin{array}{c}\text { Mandioca, carne bovina, frutas, } \\
\text { algodão, café, carne suína, carne de } \\
\text { frango, leite, cana-de-açúcar, soja, } \\
\text { milho e arroz. }\end{array}$ \\
\hline
\end{tabular}

Fonte: Elaboração dos autores.

Segundo César (2002), a forma de escoamento dos produtos das principais cadeias produtivas mineiras (mineração e siderurgia, agricultura, indústria da construção - basicamente cimento-, celulose e papel) se dá, principalmente, através de ferrovias e rodovias.

Nas vias ferroviárias, há predomínio do transporte de minério de ferro (em torno de $80 \%$ ) e pequena quantidade de líquidos e de fertilizantes (menos de 20\%). O transporte de produtos siderúrgicos, cimento e calcário é dividido entre as malhas ferroviárias e rodoviárias, porém a última ainda é o principal meio de transporte da carga industrializada, geralmente com maior valor agregado e mais dispersa geograficamente. Isso pode ser verificado na tabela 1 , a seguir:

TABELA 1 - VOLUME DE TRANSPORTE POR PRINCIPAIS AGRUPAMENTOS DE CARGA MG/1992

\begin{tabular}{lcc}
\hline Agrupamento & Milhões de Toneladas & \% Do Total \\
\hline Minero-siderúrgico & 171,3 & 49,4 \\
Granéis agrícolas, açúcar e & 26,9 & 7,8 \\
fertilizantes & 24,4 & 7,0 \\
Energéticos líquidos e gasosos & 12,0 & 3,5 \\
Outras cargas do setor agrícola & 10,8 & 3,1 \\
Indústria da construção & 3,2 & 0,9 \\
Celulose e papel & & \\
\hline
\end{tabular}

Fonte: César (2002). 
Corroborando as informações obtidas com a análise dos Quadros 1, 3, 4 e tabela 1, Santos (2006) destaca que os principais produtos que passam pelo Posto Fiscal de Matias Barbosa (MG) são: automóveis, vindos de Betim com destino a exportadores do Rio de Janeiro; móveis, originários de Ubá (MG), destinados ao Rio de Janeiro; produtos da siderurgia de Juiz de Fora em direção ao Rio de Janeiro e a São Paulo; laticínios de Juiz de Fora, Barbacena e São João Del Rei dirigidos ao Rio de Janeiro; vasilhames de indústrias de Juiz de Fora e Belo Horizonte com rumo ao Rio de Janeiro; banana natural da Bahia indo para o Rio de Janeiro; metal, calcário e zinco procedentes de Belo Horizonte rumando para o Rio de Janeiro; e cimento proveniente de Barroso (MG) com destino ao Rio de Janeiro. De acordo com o autor, o maior fluxo de mercadorias que passa pelo posto fiscal é no sentido Minas-Rio.

A análise das exportações do Estado de Minas Gerais também permite uma ratificação das informações. Através da tabela 2, verifica-se que quase $50 \%$ dos produtos exportados restringe-se a minérios e produtos siderúrgicos, o que comprova a especialização do Estado em produtos minerais.

TABELA 2 - EXPORTAÇÕES MG/ACUMULADO 1999/2005 (VALORES CONSTANTES MILHÕES DE REAIS)

\begin{tabular}{lcc}
\hline Descrição do Produto & $1999-2005$ & \% Total \\
\hline Ferro Fundido, Ferro e Aço & 30.739 & 25,67 \\
Minérios, Escórias e Cinzas & 26.883 & 22,45 \\
Café, Chá, Mate e Especiarias & 16.645 & 13,90 \\
$\begin{array}{l}\text { Veículos Automóveis, } \\
\text { Tratores: Partes/Acessórios }\end{array}$ & 10.933 & 9,13 \\
$\begin{array}{l}\text { Pastas de Madeira ou Matérias } \\
\text { Fibrosas Celulósicas }\end{array}$ & 4.610 & 3,85 \\
$\begin{array}{l}\text { Pérolas Naturais ou } \\
\text { Cultivadas, Pedras Preciosas }\end{array}$ & 3.963 & 3,31 \\
$\begin{array}{l}\text { Reatores Nucleares, Caldeiras, } \\
\text { Máquinas, Mecânicos }\end{array}$ & 3.652 & 3,05 \\
\hline
\end{tabular}

Fonte: Ministério do Desenvolvimento, Indústria e Comércio (2006).

Há também um forte peso de produtos do tipo commodities, com destaque para as cadeias do ferro e aço, café e celulose, além de automóveis, bem como suas partes e acessórios, produzidos pelas empresas automobilísticas do Estado. 
Com relação às importações (Tabela 3), o Estado de Minas Gerais adquire principalmente máquinas e insumos (matérias-primas e produtos intermediários), com destaque para os veículos automotivos e suas partes; estas últimas, fundamentais para abastecerem as empresas automobilísticas do Estado.

TABELA 3 - IMPORTAÇÕES MG/ACUMULADO 1999/2005 (VALORES CONSTANTES MILHÕES DE REAIS)

\begin{tabular}{lccc}
\hline Empresas & Região & 2005 & 2004 \\
\hline Companhia Vale do Rio Doce & Central & 12,1 & 12,7 \\
Gerdau Açominas S.A. & Central & 7,9 & 6,8 \\
Minerações Brasileiras Reunidas & Central & 7,8 & 7,0 \\
FIAT Automóveis S.A. & Central & 4,8 & 4,6 \\
Acesita S.A. & Rio Doce & 3,7 & 4,2 \\
Brasileira de Metalurgia e Mineração & Alto Paranaíba & 2,9 & 3,0 \\
Celulose Nipo Brasileira S.A. & Rio Doce & 2,9 & 3,9 \\
Usinas Siderúrgicas de Minas Gerais & Rio Doce & 2,9 & 3,3 \\
Belgo Siderúrgica S.A. & Central & 2,0 & 0,7 \\
\hline
\end{tabular}

Fonte: Fundação João Pinheiro (2006).

Essas indústrias possuem como áreas de atuação a mineração, siderurgia, metalurgia, automotiva, papel e celulose e processamento de grãos, conforme é apontado na Tabela 4.

\subsection{Destino Rio de Janeiro-Minas Gerais}

O Quadro 10 é um resumo das principais concentrações de atividade econômica das respectivas mesorregiões do Estado do Rio de Janeiro.

De acordo com Brito (2004), foram definidas 61 concentrações no Estado do Rio de Janeiro, agrupadas em 13 grandes setores de atividade econômica (agroindustrial - pecuária e pesca; petróleo; têxtil-vestuário; extração mineral e produtos de minerais não metálicos (cerâmica e cimento); papel e editorial e gráfico; petroquímico, químico e farmacêutico; metal-mecânica; mobiliário; informática; turismo; telecomunicações; audiovisual e atividades culturais e esportivas; serviços médicos e de transporte). 
BASTOS, S. \& PEROBELLI, F. \& MACIEL, M. \& DOS SANTOS, T. Plataforma logística: estudo da...

Percebe-se, pela análise do Quadro 6, que a mesorregião que concentra maior número de atividades econômicas é a metropolitana do Rio de Janeiro, com destaque para a microrregião do Rio de Janeiro.

QUADRO 6 - CONCENTRAÇÕES DE ATIVIDADES ECONÔMICAS POR MESORREGIÕES/ 2004

\begin{tabular}{|c|c|c|}
\hline Mesorregião & Microrregião & Concentrações \\
\hline \multirow[b]{2}{*}{ Baixadas } & Bacia de São João & Pecuária \\
\hline & Lagos & $\begin{array}{c}\text { Turismo - Extração de Sal - Vestuário (moda } \\
\text { praia }\end{array}$ \\
\hline \multirow{4}{*}{$\begin{array}{l}\text { Centro } \\
\text { Fluminense }\end{array}$} & Cantagalo Cordeiro & Cimento \\
\hline & Nova Friburgo & Moda Íntima - Artefatos de Metal \\
\hline & Santa Maria Madalena $(*)$ & - \\
\hline & Três Rios & $\begin{array}{c}\text { Pecuária e Carnes - Cerâmica - Veículos } \\
\text { Ferroviários - Pecuária }\end{array}$ \\
\hline \multirow{5}{*}{$\begin{array}{l}\text { Metropolitana do } \\
\text { Rio de Janeiro }\end{array}$} & Itaguaí & Extração de Pedra, Areia e Argila \\
\hline & Macacu-Caceribu & $\begin{array}{c}\text { Fabricação de Produtos Cerâmicos e Extração } \\
\text { de Pedras - Esquadrias de Metal - Pecuária - } \\
\text { Fruticultura }\end{array}$ \\
\hline & Rio de Janeiro & $\begin{array}{l}\text { Telecomunicações - Informática - Atividades } \\
\text { Culturais e Esportivas - Turismo - Editorial e } \\
\text { Gráfica - Petroquímica, Química e Plásticos, } \\
\text { Audiovisual - Farmacêutica - Vestuário - } \\
\text { Comércio de Vestuário - Fabricação de } \\
\text { Produtos Cerâmicos e Extração de Pedras - } \\
\text { Indústria Naval e Atividades Associadas - } \\
\text { Farmacêutica e Diagnóstico - Vestuário - } \\
\text { Perfumaria e Cosméticos - Mobiliário - Papel, } \\
\text { Editorial e Gráfica - Pesca - Extração de } \\
\text { Pedras e Artefatos de Concreto }\end{array}$ \\
\hline & Serrana & $\begin{array}{c}\text { Serviços Médicos - Têxtil-Vestuário - } \\
\text { Mobiliário - Aves Artefatos de Plástico - } \\
\text { Informática - Floricultura }\end{array}$ \\
\hline & Vassouras $(*)$ & - \\
\hline \multirow{2}{*}{$\begin{array}{l}\text { Noroeste } \\
\text { Fluminense }\end{array}$} & Itaperuna & Pecuária - Serviços Médicos - Têxtil-Vestuário \\
\hline & Santo Antônio de Pádua & Extração de Pedras. \\
\hline \multirow[t]{2}{*}{ Norte Fluminense } & Campos de Goytacazes & $\begin{array}{c}\text { Serviços Médicos - Cerâmica - Vestuário - } \\
\text { Produção de Açúcar - Fruticultura e alimentos } \\
\text { - Mobiliário }\end{array}$ \\
\hline & Macaé & Petróleo e Atividades Associadas. \\
\hline \multirow{3}{*}{ Sul Fluminense } & Ilha Grande $(*)$ & - \\
\hline & Barra do Píraí & $\begin{array}{c}\text { Siderurgia e associadas - Têxtil-Vestuário - } \\
\text { Pecuária e Leite }\end{array}$ \\
\hline & $\begin{array}{l}\text { Vale do Paraíba } \\
\text { Fluminense }\end{array}$ & $\begin{array}{l}\text { Siderurgia e Associadas - Automotiva - } \\
\text { Empresas de Transporte - Cimento, Artefatos } \\
\text { de Concreto e Construção - Turismo. }\end{array}$ \\
\hline
\end{tabular}

Fonte: Britto (2004)

(*) Mesorregiões sem concentrações econômicas relevantes. 
Analisando os Quadros 2 e 6, em conjunto, ou seja, excluindo-se as mesorregiões Norte Fluminense, Noroeste Fluminense e Centro Fluminense, bem como as concentrações de atividade econômica identificadas como comércio e prestação de serviços, pode-se perceber os principais produtos do Estado do Rio de Janeiro que utilizam a BR 040, quando escoados para o Estado de Minas Gerais (Quadro 7).

QUADRO 7 - PRODUTOS FLUMINENSES ESCOADOS PARA MG VIA BR O40

\begin{tabular}{|l|l|}
\hline Aglomerações Produtivas & Cadeia Agroindustrial e Agrícola \\
\hline Extração de Pedra, Areia e Argila, & \\
Cerâmicos, Plásticos, Esquadrias de & \\
Metal, Siderurgia, Petroquímica, & \\
Papel, Floricultura, Química, & Sal, Pecuária, Fruticultura, \\
Farmacêutica, Têxtil e Vestuário, & \\
Perfumaria e Cosméticos, & \\
Mobiliário, Siderurgia, Cimento, & \\
Automotiva, Artefatos de Concreto & \\
e Construção. & \\
\hline
\end{tabular}

Fonte: Elaboração dos autores.

Assim, a partir da representatividade do PIB do Estado de Minas Gerais, conciliado com a localização privilegiada de Juiz de Fora e a inexistência de Portos Marítimos em Minas Gerais, verificou-se que há um fluxo comercial internacional significativo.

Esse fluxo utiliza as vias férreas e rodoviárias que cruzam Juiz de Fora para transportar mercadorias exportadas ou importadas via os portos do Rio de Janeiro e Sepetiba e via Aeroporto Internacional do Rio de Janeiro.

Há ainda um fluxo comercial inter-regional de grande significância a utilizar as estradas rodoviárias e ferroviárias que cortam a cidade. Esse fluxo se caracteriza prioritariamente pelo transporte ferroviário de produtos siderúrgicos e o transporte rodoviário, além de alguns produtos agrícolas e agroindustriais, fundamentalmente, de produtos industrializados caracterizados como sólidos de alto peso e baixo valor agregado.

\section{Considerações finais}

O exposto anteriormente potencializa a implantação, em Juiz de Fora, de uma Plataforma Logística, no interior da qual se exerça, por diferentes operadores, todas as atividades relativas ao transporte, à logística (infra-estrutura para armazenagem, desembaraço aduaneiro, 
movimentação de mercadorias) e à distribuição de mercadorias, tanto para o trânsito nacional como para o internacional, de produtos sólidos de grande peso e baixo valor agregado. Estes produtos são de caráter constante e de grande importância tanto no cenário local quanto nacional.

Assim sendo, é possível potencializar a viabilidade de uma Plataforma Logística no município com base em evidências empíricas e teóricas. Empiricamente, é possível corroborar tal viabilidade através da análise detalhada dos fluxos de mercadorias transportadas pelas vias que cortam Juiz de Fora, como bem mostrado nas seções anteriores.

Numa abordagem teórica, como elencado na Introdução do artigo, uma Plataforma Logística deve conter, entre outros aspectos:

a) Uma subzona de transportes que agrupa grandes eixos de transporte rodoviários e ferroviários. Sabe-se que o município é cortado pela BR 040 e pela malha Ferroviária da MRS Logística;

b) Alguns microsistemas (transportadora, ferrovia, armazéns, centros de distribuição, dentre outros). E é sabido que Juiz de Fora é cortada por uma malha ferroviária, além de possuir uma Estação Aduaneira do Interior (EADI) que facilita o escoamento da produção.

Entretanto, algumas considerações devem ser feitas, já que a Plataforma Logística pode ser pública ou privada. Duarte (2004c) recomenda que a coordenação (governança) seja exercida por alguma entidade externa à cadeia logística, de forma a potencializar sua representatividade e sedimentar sua idoneidade.

Assim, caberá ao poder público municipal liderar tal processo, aglutinando as ações individuais que já ocorrem na cidade e estimulando novas iniciativas. Porém, este somente terá sucesso se inserido numa política ampla de desenvolvimento econômico para a cidade.

Ou seja, é imprescindível que o poder público encampe tal idéia e crie mecanismos não só de fomento para atração de empresas, ou parte delas, para a Plataforma, mas também que estimule a definição de um local e a construção (ou melhoramento) de suas infra-estruturas.

Associando-se às medidas ao estímulo das demais atividades da cidade, principalmente das indústrias e dos serviços locais. Assim, somente uma ação conjunta e coordenada viabilizará o sucesso de tal empreendimento.

Além disso, para a manutenção das vantagens competitivas de um sistema logístico diante de outras regiões e mercados, o governo é um fator importante de políticas, seja através de incentivos fiscais e subsídios, 
como na manutenção, modernização e ampliação de rodovias e ferrovias, melhoramento da infra-estrutura para prestação de serviços de armazenagem e movimentação de produtos, eliminação ou redução das tarifas aduaneiras e agilidade nas vistorias alfandegárias, no caso de mercadorias para o mercado externo.

Cabe destacar que quando uma cidade ou região tem sua estratégia de desenvolvimento lastreada em Logística Territorial, portanto mais dinâmica e aproveitando de modo mais racional seu espaço físico, tornase automaticamente alvo de interesse. O resultado é a migração de empresas, com profundos efeitos sobre a dinâmica da economia local, ou seja, com repercussões na ampliação da produção e do emprego do município.

Desse modo, o estudo desenvolvido aponta para a potencialidade de Juiz de Fora para sediar uma Plataforma Logística, que deve ser aproveitada pelo governo local, através do estímulo ao capital privado, seja individualmente ou em associação com o poder público (parcerias público-privadas). Sem dúvida, significaria juntar esforços objetivando transformá-la num importante centro de integração e distribuição de mercadorias.

\section{Referências}

ANDRADE, R. \& CAMPELLO, E. \& LÍRIO, V. (2000). "Transformando o Desenvolvimento da Agricultura.” Minas Gerais do Século XXI, vol IV, BDMG. Belo Horizonte: Rona Editora.

BASTOS, S. \& PEROBELLI, F. (2006). “Logística territorial e Desenvolvimento Local: viabilidade de implantação de uma Plataforma Logística em Juiz de Fora - Minas Gerais." Cadernos IPPUR/ UFRJ. Rio de Janeiro, ano XX (1):107-38.

BOUDOUIN, Daniel (1996). "Logística-Território-Desenvolvimento: o caso europeu.” Seminário Internacional: Logística, Transporte e Desenvolvimento. Ceará: UFC/CT/DET, p. 105 .

BATAlHA, Mario (1997). Gestão Agroindustrial. São Paulo: Atlas.

BRITTO, Jorge (2004). Arranjos Produtivos Locais: perfil das concentrações de atividades econômicas no Estado do Rio de Janeiro. Rio de Janeiro: SEBRAE/RJ.

CENTRO DE INFORMAÇÕES E DADOS DO RIO DE JANEIRO (CIDE) (2006). URL: http://sites.internit.com.br/cide/. Acesso em: nov. de 2006.

CÉSAR, Ramon V. (2002). "Infra-estrutura: sustentando o desenvolvimento. Transporte e Logística.” Minas Gerais do século XXI, vol. III, BDMG. Belo Horizonte: Rona Editora.

CROCCO, M. \& GALINARI, R. (200o). "Integrando a Indústria para o Futuro.” Minas Gerais do Século XXI, vol VI, BDMG. Rona Editora. 
BASTOS, S. \& PEROBELli, F. \& MACIEL, M. \& DOS SANTOS, T. Plataforma logística: estudo da...

DUARTE, P. (1999). Modelo para o desenvolvimento de Plataforma Logística em um terminal: um estudo de caso da Estação Aduaneira do Interior Itajaí/SC. Dissertação (Mestrado em Engenharia) - Programa de PósGraduação em Engenharia de Produção, Universidade Federal de Santa Catarina, Florianópolis.

DUARTE, P. (2004a). "Desenvolvimento de Plataformas Logísticas: visão estratégica e políticas públicas.” XI SIMPEP, Bauru.

DUARTE, P. (2004b). "Visão Estratégica e Impactos com a Implantação de uma Plataforma Logística.” Opinião: Especial Logística, Canoas (RS) 12(1 ${ }^{o}$ sem. $): 7-12$.

DUARTE, P. (2004c). Desenvolvimento de um mapa estratégico para apoiar a implantação de uma Plataforma Logística. Tese (Doutorado em Engenharia). Programa de Pós-Graduação em Engenharia de Produção, Universidade Federal do Rio Grande do Sul, Porto Alegre.

FUNDAÇÃO JOÃO PINHEIRO. URL: http://www.fjp.gov.br. Acesso em: 29 nov. 2006.

INSTITUTO BRASILEIRO DE GEOGRAFIA E ESTATÍSTICA (IBGE). URL: http:/ /www.ibge.gov.br/. Acesso em: abril 2006.

MARTINS, Suely Paschoalini (2006). Entrevista. Gerência de Marketing Diretoria Comercial da MRS Logística. Entrevista concedida em 06/10/ 2006.

MAPLINK. URL: http://www.maplink.uol.com.br. Acesso em: 8 dez. 2006.

MINISTÉRIO DO DESENVOLVIMENTO, INDÚSTRIA E COMÉRCIO (2006). URL: http://aliceweb.desenvolvimento.gov.br/. Acesso em: 09 nov. 2006.

ROCHA, Cézar (2006). Entrevista. Professor da Faculdade de Engenharia da UFJF e Doutor em Geografia pela UFRJ. Entrevista concedida em 07/03/ 2006.

ROCHA, Paulo (2001). Logística e Aduana. São Paulo: Aduaneiras.

SANTOS, Rodrigo (2006). Entrevista. Gestor Fazendário do Posto Fiscal de Matias Barbosa. Entrevista concedida em 14/12/2006.

TELECOTRANS (1999). "Plataformas logísticas y centros de transporte de mercancias em Espana: uma visione de la situación actual y proposta de intevencion.” URL: http://www.telecotrans.es. Acesso em: 03 dez. 2005.

Recebido em: 10 de julho de 2007 Primeira resposta em: 9 de novembro de 2007 Aceite em: 11 de junho de 2008 
BASTOS, S. \& PEROBELLI, F. \& MACIEL, M. \& DOS SANTOS, T. Plataforma logística: estudo da... 